\title{
RURAL HIGHWAY SERVICE CENTRES AND RURAL LIVELIHOODS DIVERSITY: A CASE OF NGUNDU HALT IN ZIMBABWE
}

\author{
Bernard Chazovachii, Maxwell Chuma, Lecturers \\ Great Zimbabwe University, Masvingo, Zimbabwe \\ E-mail: bchazovachii@gmail.com, maxchum@gmail.com
}

\begin{abstract}
This study seeks to assess the impact of rural high way service centres on livelihood diversity. The establishment of Ngundu rural highway service centre was an approach to assist highway travelers and local residents in accessing essential services without going offroute. Since the establishment of these highway service centers, little has been realized in terms of their utility. Data was collected using questionnaires; participatory observation and interviews and presented in the form of graphs; pie charts and tables. The rural highway service centre benefited local residents in its sphere of influence through social welfare provision; employment creation; recreation and as agricultural inputs collection centres. However the opportunity on livelihoods diversity by locals and travelers to enjoy their need has been abused. Both locals and travelers have turned the centre into risk livelihood strategies arena, crime and deviant behavior proliferated turning it into life threatening zone. Therefore need is there to reinforce overnight surveillance through the neighborhood watch for security and welfare of genuine dealers and travelers for sustainable and investment confident and promotion climate.
\end{abstract}

\section{KEY WORDS}

Rural highway service centre; Livelihood; Diversity; Ngundu halt; Zimbabwe.

Rural highway service centres are stopover towns near major transportation routes. According to the Department of Transport, Energy and Infrastructure, (2008), rural highway service centres are also called rest areas in Australia, therefore are public facilities located next to a large thoroughfare such as highway, expressway or freeway at which drivers and passengers can rest, eat, refuel without exiting on to secondary roads. Rural highway service centres have been introduced or started in different ways around the globe. In Asia for example Malaysia rural highway service centres have been started as worshiping places, (Maryland, 1995). Dickson (2003) asserted that in most parts of Asia, rural highway service centres have prayer rooms (musola) where Muslims travelling more than ninety kilometers can engage praying sessions. This make them to be centres initially established for praying sessions by Muslims.

Moreover, in Japanese English, Europe and Australia, rural highway service centres were introduced as resting places for travelers, travelling long distances (Maryland,1995).At these places this is where travelers were provided with services and facilities such toilets, eating rooms, refuel their vehicles and take refreshments. This make them to be called rest areas, hence were provided as genuine fatigue management tool and as such contained a level of facility to enable comfortable short term rest. Furthermore, in the African countries rural highway service centres were started in different way with that of the other continents, such as Europe. Wekwete (1991), asserted that rural highway service centres came in as instruments for the provision of infrastructure and services in support of agriculture in African countries such as Malawi, Zimbabwe in particular. Rural highway service centres therefore provided an opportunity to rural people as they become rationale methods for establishing outlets for agricultural inputs such as seeds, fertilizers ,implements and machine repair facilities(Matope,1993) for example in Zimbabwe rural highway service centres such as Ngundu provides inputs for agriculture which enhance people's livelihoods. In addition rural highway service centres in Africa came in as instruments for selective development investments in order to avoid spreading of financial resources too thinly, (Mutizwa-Mangiza, 1992).In Zimbabwe there is a single policy known as rural centre policy which resulted in the designation of many rural highway service centres such as Mvuma. Furthermore, in African 
continent rural highway service centres have been introduced as framework for rural poverty reduction through the provision basic needs and services particularly education and health services, (Sibanda, 1985). This was after a realization that rural areas were lagging behind in terms of development concerning the provision of basic needs and services and Perroux's 1955 Growth Pole Theory is no longer a priority. Therefore it is against this background that the research seeks to assess the impact of Ngundu rural high way service centre in rural livelihoods sustainability in its sphere of influence.

\section{STATEMENT OF THE PROBLEM}

Although the establishment of rural highway service centres was an approach to assist high way travelers and locals residents on other services, the opportunity for livelihood diversity on locals and travelers to enjoy their needs have been abused .Both local residents and travelers in transit have turned into risk livelihoods, crime and deviance hence abusing the rural highway service centres. However this has now called for an assessment into the impact on rural highway service centre rural livelihoods diversity.

Objectives: to establish the services provided at Ngundu rural highway centres; to determine the impact of rural highway service centre on rural livelihoods diversity; to recommend the rural highway services for sustainable development.

Justification of the study. This study will help residents of Ngundu rural high way service centre and its sphere of influence and the rest of Zimbabwean citizen with knowledge of diverse livelihoods opportunities, crime and deviance associated with the service centre. This would inform investors and small scale entrepreneurs' about the opportunities for expansion and development. This could educate the society to engage also in proper livelihoods strategies and not to engage in risk ones such as theft .Moreover, the study would benefit Non Governmental Organizations, villagers and ward health development committees in educating people in the society to engage in livelihood strategies which cannot put them at risk in rural high way service centres. This will also make NGOs initiate some project on life skills which can enhance livelihood strategies for the people.

\section{CONCEPTUAL FRAMEWORK}

Origin of Rural High Way Service Centres. A rural high way service centre is a public facility, located next to a large thoroughfare such as a highway, express way or free way at which drivers, passengers can rest, refuel (Australia's Department of Transport, Energy and Infrastructure, 2008). Rural high way service centres were designed for travelers to relieve themselves before encountering expected traffic jams. In the United Kingdom rural highway service centres originated as places for travelers to go to wash room (Dickson, 2003). People used these resting places during their journeys to bath their bodies. More over rural high way service centres which are also called motor way service stations in the United Kingdom were meant to accommodate fast food outlets, restaurants, small food out lets such as Mark and Spencer on and coffee shops for example, Costa coffee shops (Australia's Department of Transport, Energy and Infrastructure,2008).

In most parts of Asian countries such as Malaysia, Indonesia, Rural Highway Service Centres (RHSCs) were established for Moslems travelling more than $90 \mathrm{~km}$ to conduct praying sessions. The resting areas have prayer rooms (Musola) where the congregation can conduct a praying session during their rest (Dickson, 2003). Furthermore, RHSC in Australia had been originally established for travelers to stay overnight as a broad safety measure (Australia's Department of Transport Energy and Infrastructure 2008).Well maintained places sometimes explicitly invite travelers to rest overnight as a way of protection. This is because most long distance travelers do not have safe places to sleep during nights, so they tend to be accommodated in these areas or centres for safety reasons. Also it is these RHSC that gas stations for refueling and public phones are available for travelers.

In most African countries RHSC have originated as framework for rural poverty reduction through the provision of basic needs and services particularly education and health 
services (Sibanda, 1985).Most basic needs and services are provided by RHSCs for example in Malawi college of distance education and primary schools are offered by RHSCs. In Zimbabwe there is a single policy known as rural growth and service centre policy. RHSC has been used as an instrument for selective development investment in order to avoid spreading of scarce financial resources too thinly. This was certainly one of the main justification of Malawi's National Rural Centre Policy as well as Zimbabwe's Rural Growth and Service Centre Policy (Wekwete, 1991).So RHSC in Africa were regionally established so as to develop the rural areas and to avoid transfer of resources from rural areas as well as to alleviate poverty among the rural poor through enhancing their livelihood strategies.

More over in most African countries, RHSC have been originally established for the provision of services and infrastructure in support of agriculture (Wekwete, 1991). Agriculture is very important in its contribution to national economic production and its share for national employment. RHSC are seen as a rational way for establishing outlets for agriculture inputs such as seeds, fertilizers and implements and machinery repair facilities. These service centres have originally been seen as improving agricultural production thereby enhancing livelihood strategy. RHSCs were also established in the African context as a rational framework for the provision of facilities for the marketing of agricultural produce such as maize, both for local consumption and export outside the region. For example Grain Marketing Board Ngundu enables rural farmers to sell their maize produce hence enable the poor to reduce poverty.

Furthermore, RHSC, have been established as a mechanism for coordinating growth within newly opened and economically booming regions. This means that they coordinate growth in newly opened areas. For example in Zimbabwe, some of today's vibrant RHSC were created during the colonial period in order to stimulate rural development in agricultural production in previously neglected areas like Mhandamabwe in Chivi Zimbabwe, (Sibanda,1991). In addition RHSCs were originated as tools for redressing imbalances through the provision of infrastructure inherited from the colonial era. They have been adopted particularly for extension of roads transport, electricity and others (Matope, 1993). In Malawi development initiatives during the colonial period was concentrated in the Southern region and much northern was neglected (Matope, 1993). The national rural centre program was introduced and partly intended to redress this imbalances. In Zimbabwe, African areas were also marginalized in terms of investments development. After independence rural growth and service centres become the main policy instruments for the balanced provision of rural infrastructure and services in the African areas (Mutizwa-Mangiza, 1992). However, they later served as rest areas for travelers as they provide restaurants, eating houses etc.

Rural Highway Service Centres and Livelihood Strategies. A livelihood comprises of the capabilities, assets and activities required for a means of living (Serrat, 2008). A livelihood is a means of making a living and it represents goods and money intended for consumption. Livelihoods are measured on the basis of being correspondent to one necessities and needs. A livelihood is deemed sustainable when it can cope with and recover from stress and shocks or enhance its capabilities, assets and activities both now and in the future while not undermining the natural resources base (Serrat, 2008). A major influence on people's choice of livelihood strategies is their access to assets and policies, institution and process affect their ability to use these assets to achieve positive livelihoods outcomes. Potential livelihood outcomes can include more income, increased well being, reduced vulnerability, improved food security and many others, (Serrat, 2008). Rural people engage themselves in several livelihood strategies in most rural high way service centres such as Mhandamabwe Masvingo province, Zimbabwe. These include activities such as prostitution, vending, theft and many others. These livelihood strategies are determined by capital assets as shown by the sustainable livelihood framework below.

Serrat (2008) asserted that livelihood framework helps to organize the factors that constrain or enhances livelihood opportunities and shows how they relate to one another. RHSCs allows provision of infrastructure and services in support of agriculture in form of physical capital (Wekwete,1991).This make agriculture a major livelihood strategy to be enhanced due to the availability of these physical capital. RHSC are seen as rationale 
method for establishing outlets for agriculture inputs ,including seeds, fertilizers and many others(Sibanda,1985). Therefore, if the rural people utilized these physical capital, high agricultural production will be achieved .Moreover ,RHSC are also considered to be rational framework for the provision of the marketing facilities of agriculture produce both for local consumption and export outside the region(Matope,1993).Some rural high way service centres have managed to develop rural industries which have contributed to poverty reduction through the provision of employment.They also enhances the livelihoods of the rural people through their provision of financial capital such as credits and debts, wages and others. Rural people are provided with financial capital in order for people to enhance their livelihood through engaging in income generating activities such as poultry that would help reducing the vulnerability context in rural areas.

Moreover, Sibanda (1985) asserted that RHSC are used as framework for rural poverty reduction through the provision of basic needs such as education and health facilities as human development capitals. In Malawi the main type of RHSC are designed to offer primary education, Malawi College of distance education for learning (Matope, 1993). If people have access to education, they are employable and have potentials to do better things.

In addition, rural highway service centres provide an opportunity of rural livelihoods diversification due to the presence of several capital assets. According to Krantz, (2001), rural livelihoods diversification involves changing and growing local economies so that they no longer rely completely on one particular industry. Since diversified economies produce revenues from a variety of sources, they are far more resilient during economic downturns. Since rural highway service centres have a livelihoods diversity portfolio due to different capital assets, if a primary industry for example poultry goes into a slump, secondary industry in the same field may still be viable (Krantz, 2001).

Livelihood diversification helps to reduce shocks and constrains in households .Since rural people are able to engage in on -farm, non-farm and off-farm activities, they are given this opportunity by different capital assets in these centres (Asian Development Bank, 2000). Rural people are also able to increase their income bases due to livelihood diversification in RHSC .If rural people's income base have been increased, their asset base will also increased. However RHSC have been abused as both travelers and local people engage in risk livelihood strategies. RHSC have paved a way in risk sexual behavior as a livelihood strategy.

\section{RESEARCH METHODOLOGY}

The research used both qualitative and quantitative research methodologies. The qualitative method made use of interviews and observation while quantitatively questionnaires were used. The study population consists of 3240 , and this research used $10 \%$ of the total population. In this study the research made use of systematic random sampling in such a way that every member of the population has an equal chance of being selected in sample to avoid bias. Observation were done to validate evidence gathered using interviews and questionnaire on the services offered at Ngundu Halt and impacts of the services to the hinterland. Qualitative data was analyzed through content analysis in order to qualify the content in terms of predetermined categories and in a systematic and replicable manner. Quantitative data was analyzed using statistical package for the social science (SPSS). Sphinx survey v5 was used to complement SPSS in the analysis of qualitative data. The use of pie charts, bar charts and other statistical representation were employed in the study.

\section{RESULTS AND DISCUSSIONS}

Sex Distribution of Respondents. Both male and female equally participated in the research as shown by table one (1) below. 
Table 1 - Sex Distribution of Respondents

\begin{tabular}{|c|c|} 
& Sex \\
\hline & Male
\end{tabular}

Source: Field survey, 2012.

Age Profile of Respondents. $41+$ of the age group constituted the majority percentage (70\%), possibly due to the fact that they have much knowledge about Ngundu Halt.21-40 years range has the medium size of respondents which constitutes $20 \%$ and finally 20 years and below constitute $10 \%$ respectively as shown in figure 1 below.

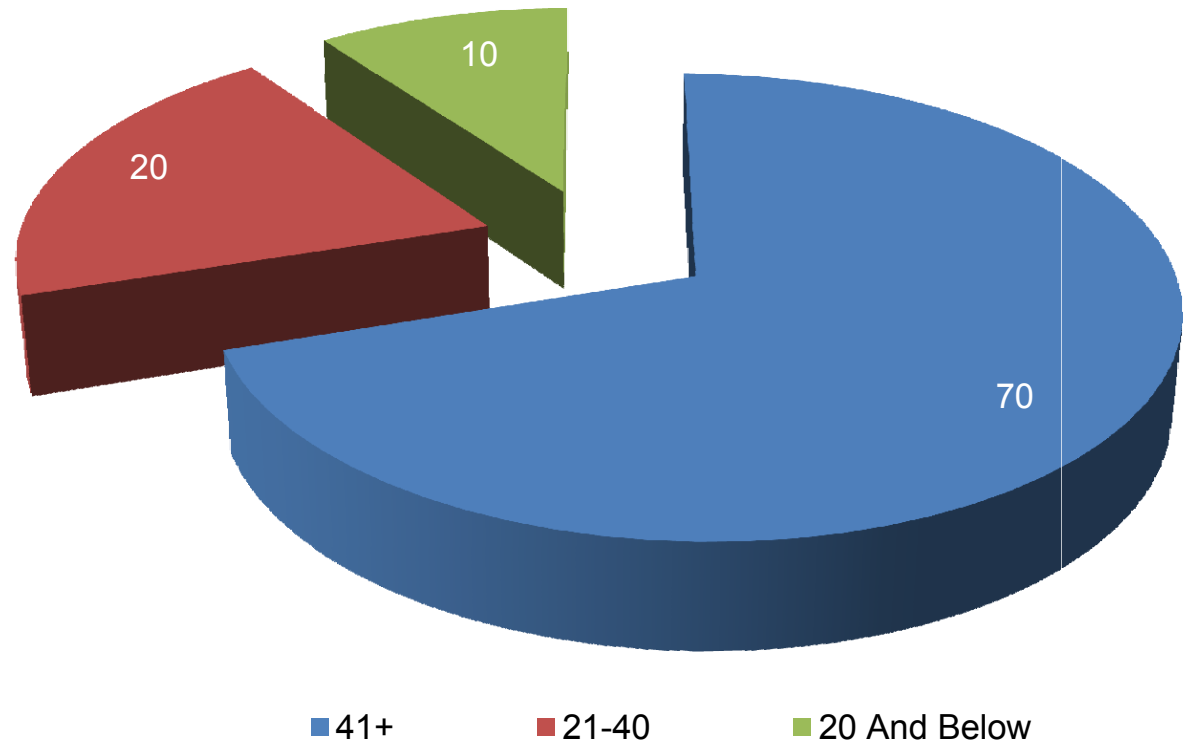

Figure 1 - Age distribution of respondents

Education Profile of Respondents. The educational levels of respondents ranged from those with primary level to those with tertiary level. Those with primary level of education were the majority followed by secondary and tertiary respectively as shown in figure 2 below.

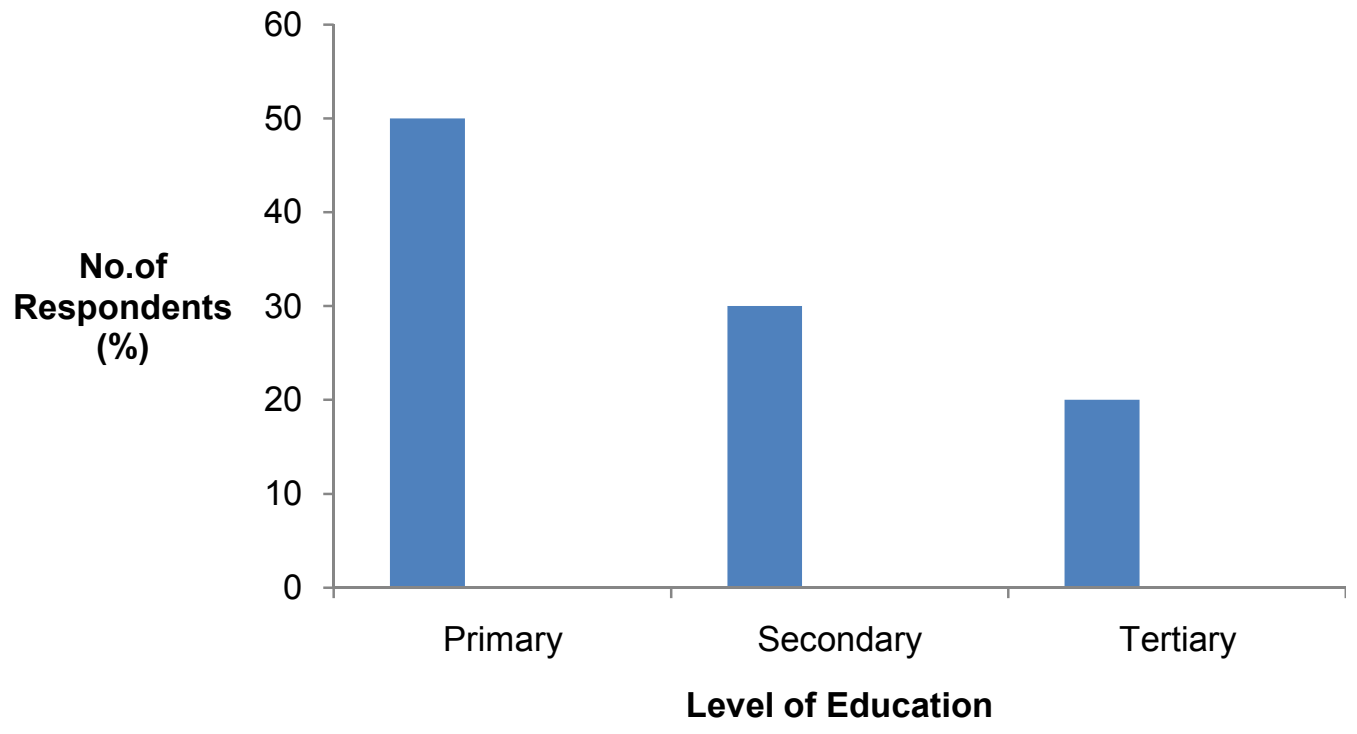

Figure 2 - Educational profile of respondents 
Services offered at Ngundu RHSC. Majority of respondents noted that Ngundu halt offer both formal and informal activities to improve people's livelihoods.

Table 2 - Formal and Informal Activities at Ngundu

\begin{tabular}{|c|c|}
\hline FORMAL ACTIVITIES & $\begin{array}{l}\text { INFORMAL } \\
\text { ACTIVITIES }\end{array}$ \\
\hline Poultry projects & Illegal fuel dealing \\
\hline Health services: Ngundu rural health centre & $\begin{array}{l}\text { Illegal money } \\
\text { exchange }\end{array}$ \\
\hline Veterinary services & Commercial sex work \\
\hline Agriculture and extension services & Illegal vending. \\
\hline Retail shops for example :Marufu; Mazondo & 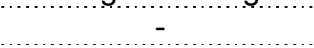 \\
\hline Post Office Bank & - \\
\hline $\begin{array}{l}\text { Lodge and restaurants: which are Chakalaka and Marufu restaurants and } \\
\text { Nemhungwedza lodge }\end{array}$ & - \\
\hline Cotton companies, for example COTTCO & $\begin{array}{cc}- \\
-\end{array}$ \\
\hline Beer halls offered by Ngundu Rural District Council and Hungoedza Beer hall & - \\
\hline Schools which are Ngundu Halt high school and Madzivire primary school & $\begin{array}{cc}- \\
\cdots\end{array}$ \\
\hline Farm supplies & - \\
\hline
\end{tabular}

Source: Field Survey, 2012.

Impact of the services on the Surrounding Neighborhoods' Livelihoods. Services offered at Ngundu halt have affected the surrounding hinterland especially in ward 26, 25 and 24 by bringing agricultural support services such as cotton companies; veterinary services; farm supplies and agriculture rural extension (AREX) to the door steps as shown in table 2 above. Extension services educate people about seed varieties applicable in the surrounding area, amount of fertilizer needed for a seed variety and time of planting .Veterinary also educate people about animal husbandry so that livestock can be protected from diseases. Cotton companies, such as COTTCO, engage in contract farming with the surrounding communities. The partnership between cotton companies and the community make people access to agricultural inputs such as seeds; agrochemicals and markets of their products. Existence of Farm Supplies such as Masvingo farm supply at Ngundu make farmers' access to agriculture inputs such as credit facilities, agrochemicals etc.

Other respondents indicated that the existence of Ngundu halt resulted in livelihood diversification in the surrounding communities. They indicated that, this has enabled them to engage in off-farm and on-farm activities simultaneously. In the hinterland, people are engaged in the agriculture practices such as crop production. They mix up this with waged labour at the centre hence making it possible to improve income base. Livelihood diversification helps to prevent shocks such as droughts. Ngundu halt has brought about employment opportunities to the surrounding communities such as ward 25; 23 and 26.

The availability of commercial activities such as retail shops; flee markets; vending and others make people access to basic commodities such as food; clothes; building materials and others. This has improved the standard of living since people are able to have good shelter; quality food; clothes. Therefore the existence of these commercial activities impacted positively the surrounding neighborhood's livelihoods.

However, some villagers argued that commercial activities (both formal and informal) offered at Ngundu halt has brought about risk sexual activities as a livelihood strategy. According to Mann (2003), the existence of beer halls; lodges and other activities, at RHSC made the areas to be fertile grounds for risk sexual behavior. At Ngundu most women enter into prostitution with travelers, especially truck drivers for commercial purposes resulting in proliferation of sexually transmitted diseases. Ngundu health centre revealed that sexually transmitted diseases (STD) are at $67,3 \%$ this year. This resulted in many deaths leading to shortage of agriculture labour hence affecting the agriculture productivity as a livelihood development strategy.

Ngundu halt has brought about Post office savings bank which has managed to reveal loans to the surrounding communities such as Madzivire; Shindi of the three wards. This 
enabled the rural people to initiate income generating projects such as poultry; wielding and night school education. Moreover, respondents also noted that they managed to access remittances from their relatives through post office bank. Remittances enabled them to access their basic needs such as food; education and assets.

\section{CONCLUSION}

Drawing from the data that was collected, Ngundu RHSC has to a larger extent contributing to the development of the surrounding rural community. This is depicted by the provision of social services such as of health and educational facilities which has resulted in a magnificent change in the human development index such as increased literacy rate and reduced disease outbreaks. The findings also noted that Ngundu RHSC provided employment to the surrounding community that is both formal and informal and this has improved the livelihood of the people. Due to the existence of POST office bank at Ngundu, access to loans and remittances have become easy and this gave rise to income generating activities which is making surrounding communities access to income which better their standard of living. The livelihood diversification promoted by Ngundu RHSC has made people to increase their income base and also to reduce shocks and constrains such as droughts. The results also depicted that the existence of AREX; cotton companies has made it possible for sustainable agricultural development through contract farming and conservation agriculture promotion .However, the research noted that since Ngundu RHSC resulted in people taking risk livelihood strategies such as prostitution, this has caused high death of most young and energetic people hence living the community without economically active group. Moreover ,Chivi rural district council should provide access to vending licenses to the surrounding communities for them to access vending hence improving the livelihoods of the people in the surrounding areas such Madzivire ;Shindi and others. The government through the Ministry of Agriculture should resuscitate Grain Marketing Board (GMB) mandate of providing agriculture inputs such as seeds; fertilizers to the surrounding community such as ward 25; 26 and others so as to improve agriculture productivity. For sustainability and sustainable development to prevail at rural highway service centres, government like what it has done on growth points, should give support through investment, incentive so that these would also act as nodes of development apart from the known growth centres characterized by stunted growth and some termed them declining centres.

\section{REFERENCES}

[1] Serrat, J. (2008) The Sustainable Livelihood Approaches, Philippines, Metro Manila.

[2] Dickson, G. (2003) Government Work Zone. Fortworthstar, Telegram 4 Sec Metro.

[3] Department of Transport, Energy and Infrastructure (2008), (Revision 7). South Australia.

[4] Krantz, L. (2001) The Sustainable Livelihood Approach to Poverty Reduction: An Introduction, SIDA, Division For Policy And Socio-Economic Analysis.

[5] Matope, M. (1993) Improving Rural Regional Settlements Systems Management. Mkhota Rural Service Centre and Kasungu District, Malawi.

[6] Mtizwa-Mangiza N.D. (1992) Human Settlements Policies in Zimbabwe with Special References to Shelter Development Dialogue Volume 13 Number 14.

[7] Mann, F (2003) National Oceanic and Atmospheric Administration, Department of Natural Science, USA, University of Virginia.

[8] Sibanda. H. (1985) Growth Points: Focus for Rural Development, Department of Rural and Urban Planning, Harare, University of Zimbabwe publishers.

[9] Wekwete K. H. (1991).Growth Point Policy in Zimbabwe. Aldershot: Avebury. 